УДК $33: 338$

\title{
СОЦИАЛЬНЫЕ МАКРОГРУППЫ В МЕХАНИЗМЕ ОБЕСПЕЧЕНИЯ СБАЛАНСИРОВАННОГО РАЗВИТИЯ
}

\author{
А.И. ЛУЧЕНОК \\ д-р экон. наук, проф., заведующий отделом макроэкономической и финансовой политики \\ Института экономики НАН Беларуси, г. Минск
}

\begin{abstract}
Аннотация
Для согласования экономических интересов на макроэкономическом уровне предложено ввести в экономический оборот термин «социальная макрогруппа», под которой понимается объединение людей со специфической ролью в экономической деятельности, способных влиять на основные макроэкономические пропориии и существенно корректировать финансовые потоки в экономике. С учётом этого предложения рекомендованы меры по разработке инструментов регулирования системы неформальных институтов, позволяющих эффективно согласовывать экономические интересы социильных макрогрупп с изелью получения максимального эффекта от использования всех видов материальных, трудовых и финансовых ресурсов.
\end{abstract}

\section{Abstract}

To harmonize economic interests at the macroeconomic level the author suggests to define the term "social macrogroups" as the coalescence of people according to specific role in economic activities. These groups could influence main macroeconomic proportions and financial flows in the economy substantially. In view of this proposal some steps to develop regulatory tools of informal institutions are recommended. They are intended to help effectively coordinate economic interests of social macrogroups in order to obtain maximum benefit from material, labor and financial resources.

\section{ВВЕДЕНИЕ}

В экономической литературе существуют различные подходы к определению понятия «сбалансированный экономический рост». Достаточно распространена трактовка этого термина как траектории развития, при которой все переменные растут с постоянной скоростью [1]. Такой подход имеет право на существование только в том случае, если экономика уже сбалансирована и основные пропорции нужно просто поддерживать в сложившемся соотношении. Однако другая ситуация складывается при дисбалансе между потреблением и накоплением, между экспортом и импортом, гипертрофированном развитии одних отраслей и недостаточной развитостью других. В этом случае для обеспечения сбалансированного развития необходимо менять соотношение основных народнохозяйственных пропорций, в частности, стимулировать накопление, экспорт, поощрять развитие одних отраслей при ослаблении стимулирования деятельности других.

Общим критерием оценки степени развития отраслей может стать их роль в производстве добавленной стоимости в расчете на одного работника. На практике этот критерий нуждается в уточнении, поскольку необходимо учитывать сопряженность (спрос) и потенциальную рентабельность производимых товаров, работ и услуг, а также степень их инновационности. Условным примером может быть производство хомутов: до тех пор, пока для хозяйственных нужд будут использоваться лошади, хомуты будут нужны, но это не значит, что их производство следует расширять для роста добавленной стоимости в расчете на одного скорняка.

Более приемлемой, на наш взгляд, является трактовка, по которой под сбалансированным ростом понимается устойчивое развитие в долгосрочной перспективе без серьезных спадов и подъемов [2]. При этом особенностями сбалансированного экономического развития являются следующие характеристики:

- экономика развивается темпами, близкими к долгосрочному тренду экономического роста;

- низкая инфляция;

- сбалансированность между различными секторами экономики;

- сбалансированность между различными регионами страны;

- баланс между потреблением и инвестициями;

- экологическая сбалансированность, предполагающая по возможности широкое использование возобновляемых ресурсов экономического роста.

Между тем, одним из синонимов прилагательного «сбалансированный» является прилагательное «согласованный» [3], что отражает важный аспект обеспечения сбалансированного экономического роста - согласования интересов участников экономической деятельности независимо от того, в какой форме они выступают: в виде социальных групп или отдельных работников.

В связи с этим, в макроэкономическом плане сбалансированный экономический рост целесообразно трактовать как обеспечение положительной динамики макроэкономических показателей без значительных колебаний их значений на протяжении достаточно длительного периода времени на основе согласования экономических интересов всех участников экономической деятельности. Темпы устойчивого роста должны обеспечивать соответствие наличных 
ресурсов объему совокупного спроса, что позволяет исключить необходимость повышения цен на факторы производства ввиду их нехватки. При определении понятия качества экономического роста следует исходить из необходимости достижения таких пропорций развития национальной экономики, при которых монетарная и фискальная системы будут устойчивы и распределение ресурсов будет ориентировано на обеспечение аллокативной эффективности.

Стратегической целью сбалансированного развития является улучшение согласования интересов всех социальных групп общества в направлении повышения эффективности национальной экономики.

\section{РЕЗУЛЬТАТЫ И ИХ ОБСУЖДЕНИЕ}

Под социальными группами понимаются объединения людей со специфической ролью в экономической деятельности и обществе, связанных системой взаимных отношений, которые регулируются формальными или неформальными нормами (институтами). При этом социальные группы, в отличие от массовых общностей, характеризуются:

- устойчивым взаимодействием, которое способствует стабильности их существования в пространстве и во времени;

- относительно высокой степенью сплоченности;

- отчетливо выраженной однородностью состава, т. е. наличием признаков, присущих всем индивидам, входящим в группу;

- вхождением в более широкие общности в качестве структурных образований [4].

В научной литературе также используется понятие так называемых «больших социальных групп», к которым, в частности, относятся социальные классы, профессиональные группы, половозрастные группы (молодежь, женщины, пожилые люди и т.д.) [5]. Большими социальными группами являются также работники отдельных отраслей или видов экономической деятельности, индивидуальные предприниматели, пенсионеры, учащиеся и проч. При этом представители этих групп имеют возможность транслировать свои потребности, преобразуемые в интересы, лицам, обеспечивающим или способным обеспечить их реализацию.

Вместе с тем для целей макроэкономического анализа понятие «большие социальные группы» нуждается в уточнении, поскольку далеко не все из этих групп добровольного или вынужденного объединения людей, ориентированных на реализацию общих интересов своих членов в отношениях с другими группами интересов и внешней средой, обладают влиянием, которое позволяет им серьезно воздействовать на основные макроэкономические пропорции, определять специфику монетарной, фискальной и институциональной политики, существенно корректировать финансовые потоки в экономике. Такие укрупненные группы нами предлагается назвать социальными макрогруппами (СМГ). Они предназначены для реализации следующих функций:

во-первых, агрегирование интересов членов социальной макрогруппы, установление иерархии между интересами по степени приоритетности с выработкой на этой основе общегрупповых целей. При этом предполагается не только определение наиболее значимых целей, но и прогнозирование возможности их реализации;

во-вторых, разработка мероприятий по реализации интересов СМГ путем транслирования своих интересов в органы государственного управления и взаимодействия с этими структурами;

в-третьих, участие в подборе кадров, выдвижении своих представителей в органы государственного управления для реализации своих групповых интересов;

в-четвертых, использование средств массовой информации для пропаганды своих интересов как в прямой, так и в завуалированной форме.

Как правомерно отметил В. Мау, «борьба между различными социально-экономическими группировками («группами интересов», оформляющимися в соответствующие политические или чисто лоббистские организации) за приоритеты экономической политики имеет место во всех странах и во все времена... Эти группы должны быть непосредственно связаны с экономическими процессами, с производством и обращением, с банковской деятельностью и т.П... А основным критерием их разделения, дифференциации должна выступать объективная заинтересованность в осуществлении определенного типа экономической политики, то есть в осуществлении государственной властью некоторого комплекса мероприятий, отвечающих интересам данных хозяйственных структур и тем самым, по их представлению, полезных и нужных всему народному хозяйству» [6].

Исходя из анализа финансовых потоков и предпринимаемых мер государственного регулирования считаем, что доминирующими социальными макрогруппами в белорусской экономике являются:

- СМГ «Индустриально-промышленный комплекс»;

- СМГ «Аграрно-продовольственный комплекс»;

- СМГ «Строительный комплекс»;

- СМГ «Банковско-финансовая сфера»;

- СМГ «Домашние хозяйства» (население).

Определенную роль в перераспределении ресурсов играют социальные макрогруппы «Мелких и средних предпринимателей», «Научно-исследовательский и внедренческий комплекс», «Медицина», «Транспортный комплекс» в тех случаях, когда они отражают интересы, расходящиеся с интересами доминирующих СМГ.

В состав социальных макрогрупп считаем нецелесообразным включать органы государственного управления, хотя некоторые из них по своим интересам смыкаются с профильными социальными макрогруппами. Например, Национальный банк Республики Беларусь частично является органом, выражающим интересы банковско-финансовой 
макрогруппы, Министерство промышленности (Минпром) ориентировано на обслуживание интересов индустриально-промышленной макрогруппы, Министерство сельского хозяйства и продовольствия (Минсельхозпрод) тесно взаимодействует с СМГ аграрно-продовольственного комплекса, а Министерство архитектуры и строительства (Минстройархитектуры) - со строительной социальной макрогруппой. Ряд министерств представляют интересы макрогруппы домашних хозяйств (населения). Однако указанные органы государственной власти обязаны прежде всего реализовывать общегосударственные интересы, а в отношении профильных социальных макрогрупп должны выступать, с одной стороны, как помощники, а с другой - как контролеры и проводники государственной политики. В результате, в целом выполняя задачу реализации общегосударственных интересов, возникают противоречия на более низком уровне между органами государственной власти по поводу реализации представляемых ими отраслей или секторов экономики.

Рассмотрим противоречия и проблемы согласования экономических интересов социальных макрогрупп на примере монетарной (денежно-кредитной) политики.

Подходы к монетарной методологии содержались в трудах И. Фишера, А. Маршалла, А. Пигу и других авторов. Однако комплексное рассмотрение проблем монетарного регулирования было дано в трудах М. Фридмана. В последующий период проблемы денежно-кредитного регулирования продолжали активно исследоваться и инструменты монетарной политики стали составным элементом государственного управления экономикой. Реализация этой политики в нашей стране осуществляется Национальным банком Республики Беларусь, который реализует свои функции с помощью следующих основных инструментов:

- изменение предложения денег, которое осуществляется Национальным банком Республики Беларусь (далее Национальным банком, НБ) путем изменения нормы обязательных резервов банков второго уровня (далее - банков) и, следовательно, влияя на их кредитные возможности).

- изменение учетной ставки процента (ставки рефинансирования);

- операции на открытом рынке.

Монетарные инструменты применяются для достижения стоящих перед Национальным банком целей, то есть обеспечивается реализация государственных интересов через этот орган регулирования. Вместе с тем, возникает вопрос, в чем выражаются эти интересы в сфере монетарной политики.

Распространена точка зрения, что одной из основных целей государственного регулирования является подавление инфляции [7]. Похожая трактовка гласит, что «антиинфляционная политика - это комплекс мер по регулированию экономики, направленных на борьбу с инфляцией» [8]. То есть, авторы такого подхода предполагают, что инфляция сама по себе зло и с ней непременно нужно бороться, желательно до полной победы.

Другие авторы придерживаются более взвешенного подхода к регулированию инфляционных процессов. В частности, есть мнение, что главная цель антиинфляционной политики - сделать инфляцию управляемой и ослабить ее негативные социально-экономические последствия [9]. Так считает, например, М.Ю. Малкина, которая попыталась найти ответ на вопрос, нужно ли вообще ликвидировать инфляцию путем радикальных мер или более предпочтительно адаптироваться к ее относительно невысоким темпам. Ею был сделан вывод, что цель антиинфляционной политики заключается в том, чтобы сделать инфляцию управляемой, а ее уровень - достаточно умеренным [10]. Такой подход нам представляется наиболее обоснованным, поскольку умеренная кредитная эмиссия позволяет стимулировать экономический рост.

В настоящее время Национальный банк проводит политику таргетирования инфляции. В «Основных направлениях денежно-кредитной политики Республики Беларусь на 2014 год» целью денежно-кредитной политики, реализуемой совместно с мерами экономической политики, проводимой Правительством Республики Беларусь, определено снижение инфляции, измеряемой индексом потребительских цен, до 11 процентов (декабрь 2014 г. к декабрю 2013 г.) $[11]$.

Возникает вопрос о том, чьим интересам соответствует снижение темпов инфляции. Прежде всего, это выгодно социальной макрогруппе домашних хозяйств и особенно той части населения, которое получает оплату труда из бюджетных средств: известно, что в условиях повышенных темпов инфляции потери населения от роста цен компенсируются из бюджета со значительным отставанием и не обязательно в полном размере.

В целом ограничение темпов инфляции соответствует и интересам нефинансового сектора национальной экономики, поскольку в этом случае снижается ставка рефинансирования и удешевляются кредиты. Но следует учитывать, что инфляция возникает как в финансовом, так и нефинансовом секторе.

Сторонники монетаристского подхода считают, что инфляция обусловлена исключительно проводимой денежно-кредитной политикой. При этом обычно ссылаются на высказывание М.Фридмена о том, что инфляция всегда и везде есть монетарный феномен, не упоминая при этом вторую часть предложения, в которой речь идет только о случае опережающего роста количества денег над выпуском[12].

Переполнение денежных каналов сверх потребностей реального выпуска действительно обусловливает монетарную инфляцию. Но опережающий рост денежной массы по сравнению с товарным предложением обычно обусловлен обстоятельствами, которые вынуждают монетарные власти нарушать отработанные подходы к регулированию денежно-кредитной сферы. Это обусловлено тем, что система законодательных актов, регулирующих денежнокредитную деятельность, в основном сбалансирована с учетом интересов различных социальных макрогрупп путем согласования проектов документов с Национальным банком Республики Беларусь. В результате реализация запросов индустриально-промышленной, аграрно-продовольственной, строительной и некоторых других макрогрупп нефинансового сектора экономики требует дополнительных финансовых ресурсов, которые можно получить за счет активизации кредитования, которое в ряде случаев может носить инфляционный характер. То есть, позиционируя себя как 
проводника монетаристского подхода, Национальный банк вынужден отступать от теоретико-методологической выверенности принципов и идти навстречу потребностям реального сектора экономики.

Рост кредитования экономики, в том числе за счет эмиссии Национального банка, соответствует и интересам банковско-финансовой социальной макрогруппы. Причем, в данном случае заинтересованность этой макрогруппы является непротиворечивой в отличие от интересов макрогрупп сфер производства и услуг. С одной стороны, они хотят дополнительных кредитов, усиливающих разрыв между денежной и товарной массой и стимулирующих инфляцию, но, с другой стороны, они хотят дешевых кредитов за счет снижения ставки рефинансирования вследствие минимизации темпов инфляции. В результате возникает противоречие, стимулирующее дисбалансы в экономике.

Одним из вариантов решения проблемы обеспечения низких процентных ставок при достаточно высоких темпах инфляции является предоставление льготирования процентных ставок за счет средств государственного бюджета. Но в этом случае страдают социальные макрогруппы, которые в значительной части финансируются именно за счет бюджета. В результате в государственном бюджете уменьшается доля средств, выделяемых на нужды социальной макрогруппе «домашние хозяйства». Для сокрытия возникающих при этом противоречий соответственно формируется структура принимаемых государственными органами документов. Например, в приложении 3 «Расходы республиканского бюджета по функциональной классификации расходов бюджета по разделам, подразделам и видам расходов» в Законе Республики Беларусь «О республиканском бюджете на 2014 год» в раздел «Социальная политика» включена статья «Помощь в обеспечении жильем» в сумме 2771,5 млрд руб., что в 883 раза больше расходов на социальную защиту и всего в 2,2 раза меньше выделяемых средств на пенсионное обеспечение населения страны [13]. Между тем, за счет средств по указанной статье финансируется строительство льготного жилья, которое создает искусственный спрос на квартиры и лоббируется в первую очередь социальной макрогруппой «Строительный комплекс». Поэтому в 1 полугодии 2014 г. доля льготных кредитов составила 27,9\% от инвестиций в основной капитал в жилищном строительстве [14].

В то же время по данным соцопросов в системе приоритетов СМГ «Домашние хозяйства» жилищная проблема вызывает беспокойство только у 28,5\% опрошенных. Примерно на аналогичном уровне у населения вызывают тревогу проблемы воспитания молодежи, низкий уровень культуры населения, преступность (22\%). Даже алкоголизм нервирует население больше $(40,5 \%)$, чем вопросы обеспечения жильем. В то же время наиболее актуальной проблемой является рост цен - ее отметили 71,5\%, в том числе на продукты питания - 64\% [15].

В результате становится очевидным, что даже в основе инфляции по М. Фридмену лежит не свободная воля монетарных властей, а необходимость удовлетворения запросов представителей социальных макрогрупп, направленных на реализацию своих интересов.

При ускорении темпов инфляции из-за снижения курса национальной валюты также происходит разнонаправленная борьба различных интересов. С одной стороны, в девальвации национальной валюты заинтересованы:

(а) экспортеры для повышения конкурентоспособности своих товаров и услуг за границей;

(б) отечественные производители, ориентированные на внутренний рынок и противодействующие увеличению дешевого импорта;

(в) органы государственного управления, отвечающие за сбалансированность внешнеторгового сальдо.

При этом достаточно высокие темпы инфляции позволяют перераспределять ресурсы в пользу банковской социальной макрогруппы. В условиях высоких темпов инфляции обеспечивается более легкое наполнение государственного бюджета с соответствующим увеличением его расходов.

С другой стороны, в устойчивости белорусского рубля и росте зарплат в долларовом выражении заинтересовано население, импортеры товаров и услуг, органы государственного управления, отвечающие за социальную политику, а также Национальный банк Республики Беларусь, который, в соответствии с уставом, должен обеспечивать защиту и устойчивость белорусского рубля, в том числе его покупательной способности и курса по отношению к иностранным валютам [16].

Наряду с регулированием инфляции в Республике Беларусь важной задачей денежно-кредитной политики является обеспечение достаточно высоких и стабильных темпов экономического роста. В частности, в Программе социально-экономического развития Республики Беларусь на 2011-2015 гг. запланировано увеличение ВВП в целом за пятилетку на 162-168\%. Достижение этой цели требует активизации инвестиционной активности экономических субъектов. В условиях, когда до сих пор не созданы необходимые институциональные условия для привлечения зарубежных инвестиций, возникает проблема стимулирования внутренних инвестиций, в том числе за счет финансовых ресурсов домашних хозяйств.

За 2013 г. население Республики Беларусь инвестировало средства в основной капитал (преимущественно в жилищное строительство) в размере 17,4 трлн. рублей. За тот же период чистый прирост депозитов населения в национальной и иностранной валюте достиг 23,1 трлн. рублей. При этом чистый прирост кредитов населения составил 13,8 млрд. рублей, из них на потребительские нужды - 4,6 трлн. рублей, кредиты на финансирование недвижимости - 9,2 трлн. рублей (в том числе кредиты на строительство (реконструкцию) и приобретение жилья - 9,0 трлн. рублей), а 9,2 трлн. рублей было направлено на кредитование других отраслей экономики. При этом задолженность по долгосрочным кредитам выросла за 2013 г. на 45,8 трлн. рублей, а по краткосрочным кредитам - на 11,7 трлн. рублей. То есть, правомерно считать, что $80 \%(45,8 /(45,8+11,7) * 100)$ кредитных средств пошли в долгосрочные инвестиции.

Таким образом, за счет средств домашних хозяйств было осуществлено инвестиций на сумму 16,6 трлн. рублей $(9,2+9,2 * 80 / 100)$. В то же время иностранные инвестиции (без кредитов банков) составили в том же году всего 6,7 трлн. рублей, то есть в 2,5 раза меньше, чем инвестировали домашние хозяйства. Но, если для привлечения средств иностранных инвесторов осуществляются различные комплексы мероприятий, то для привлечения средств населения 
в инвестиционный оборот серьезной работы не ведется. В стране практически отсутствует рынок ценных бумаг, на котором население могло бы осуществлять инвестиции с получением доходов как за счет дивидендов, так и за счет роста курсовой стоимости акций. Нет также системы накопительного страхования и практически отсутствуют негосударственные пенсионные и инвестиционные фонды для населения. Имеющуюся практику покупки банковских сертификатов и облигаций следует рассматривать как форму депозитов, а ограниченную по масштабам покупку драгоценных металлов можно рассматривать как форму сбережения, но не инвестирования. Таким образом, депозиты и их разновидности остаются практически единственным источником инвестирования средств домашних хозяйств в национальную экономику.

Домашние хозяйства с осторожностью относятся к хранению денег в рублевых депозитах из-за опасения серьезной девальвации белорусского рубля, обесценивающей рублевые вклады. Поэтому депозиты в белорусских рублях в белорусской банковской системе в сентябре 2014 г. снизилась по сравнению с предшествующим месяцем на 90 млрд. рублей и составили 45003 млрд. рублей (рисунок 1).

Величина депозитов в иностранной валюте в 1,8 раза больше, чем в белорусских рублях. Но, с другой стороны, постоянное отрицательно сальдо текущего счета платежного баланса создает опасения у населения по поводу возможности замораживания валютных вкладов. Кроме того, сравнение депозитных ставок по белорусским рублям и иностранным валютам создает впечатление заниженности ставок по валютным депозитам. Поэтому в результате дисбаланса интересов (сохранения денежных активов и стремления зарабатывать на них) население сохраняет значительную часть финансовых ресурсов в наличной форме, а нефинансовый (реальный) сектор продолжает испытывать потребность в инвестициях. В частности, по данным С. Румаса и А. Плешкуна к концу 2009 г. банками было привлечено от населения 18,2 трлн. руб. на счета и 0,6 трлн. руб. - в виде вложений в ценные бумаги. При этом запасы наличной иностранной валюты составляли 11,9 трлн. руб. [17]. К настоящему времени ситуация принципиально не изменилась, что свидетельствует о необходимости серьезного учёта интересов СМГ «Домашние хозяйства» при определении ставки рефинансирования и ставок как рублевых, так и валютных депозитов. Недостаточный учет интересов населения привел к тому, что в 2014 г. в структуре предоставляемых кредитов на долю финансирования свыше года приходится менее $20 \%$ как в национальной, так и в иностранной валюте. Это обусловлено спецификой депозитов - $90 \%$ срочных вкладов заключаются на срок до 1 года [18].

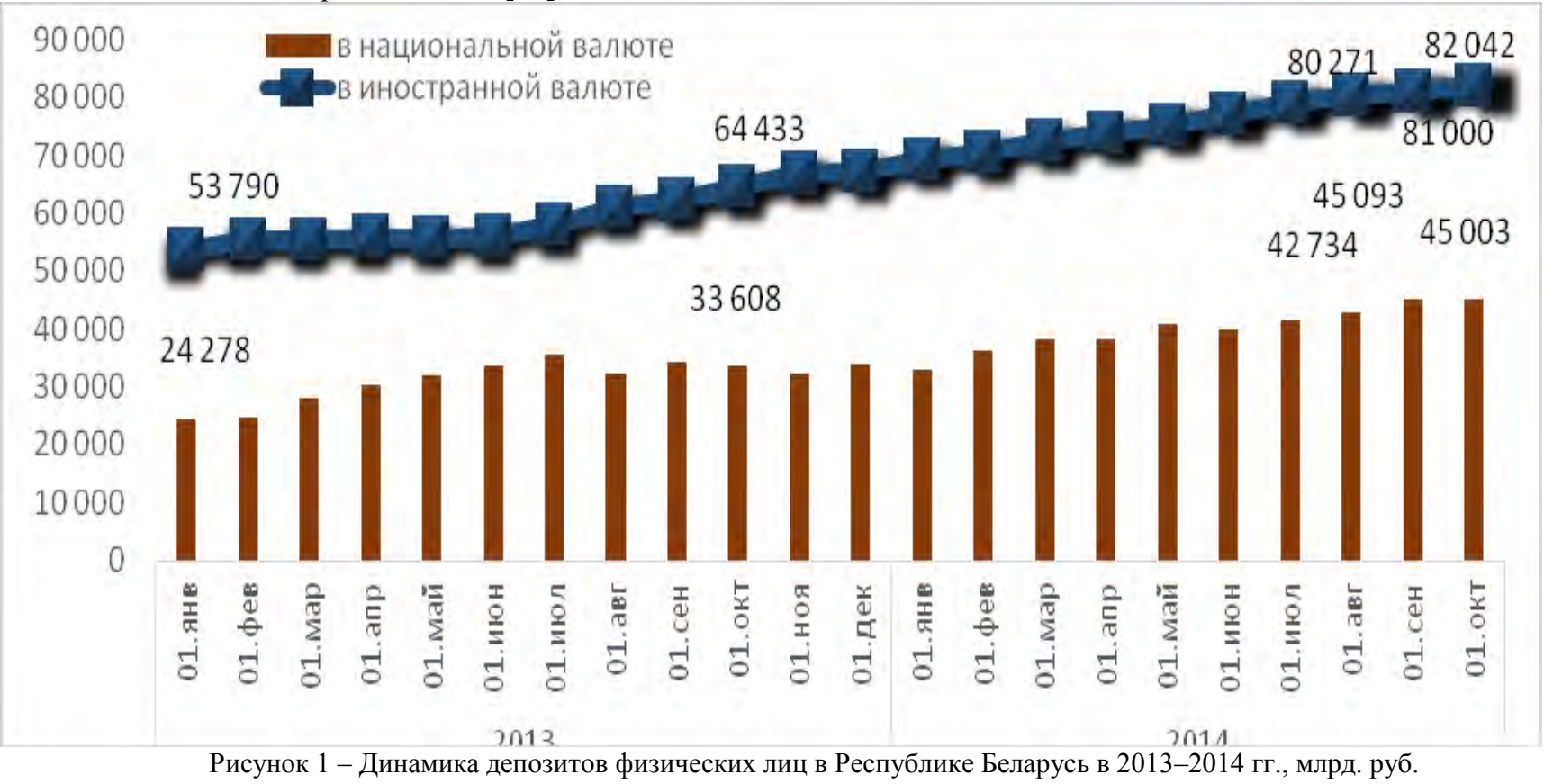

При этом Национальный банк, уступающий требованиям социальных макрогрупп нефинансовой сферы по снижению процентных ставок, вынужден ущемлять интересы социальной макрогруппы «домашние хозяйства» в высоких депозитных ставках, понижая ставку рефинансирования. В ряде случае это ведет к снижению интереса к рублевым депозитам. Так, снижение ставки рефинансирования в 1 полугодии 2013 г. с 30\% до 23,5\% привело к постепенному снижению темпов помесячного прироста рублевых депозитов. Лишь к сентябрю 2013 г. население адаптировалось к новым процентным ставкам по рублевым депозитам (рисунок 2).

Дальнейшее понижение процентных ставок привело к возникновению противоречий не только между Национальным банком и населением, но и скрытому противодействию со стороны банков второго уровня. Для стимулирования привлечения депозитов банки были вынуждены в определенной степени игнорировать снижение процентной ставки. В частности, на середину октября 2014 г. при ставке рефинансирования 20\% ряд банков (в том числе ОАО «Белинвестбанк», ОАО «Белгазпромбанк» и др.) за годовой депозит предлагали вознаграждение в размере 28-32 процентов. Именно такая политика банков позволила обеспечить прирост рублевых депозитов и ослабление роли ставки рефинансирования как инструмента монетарного регулирования. 


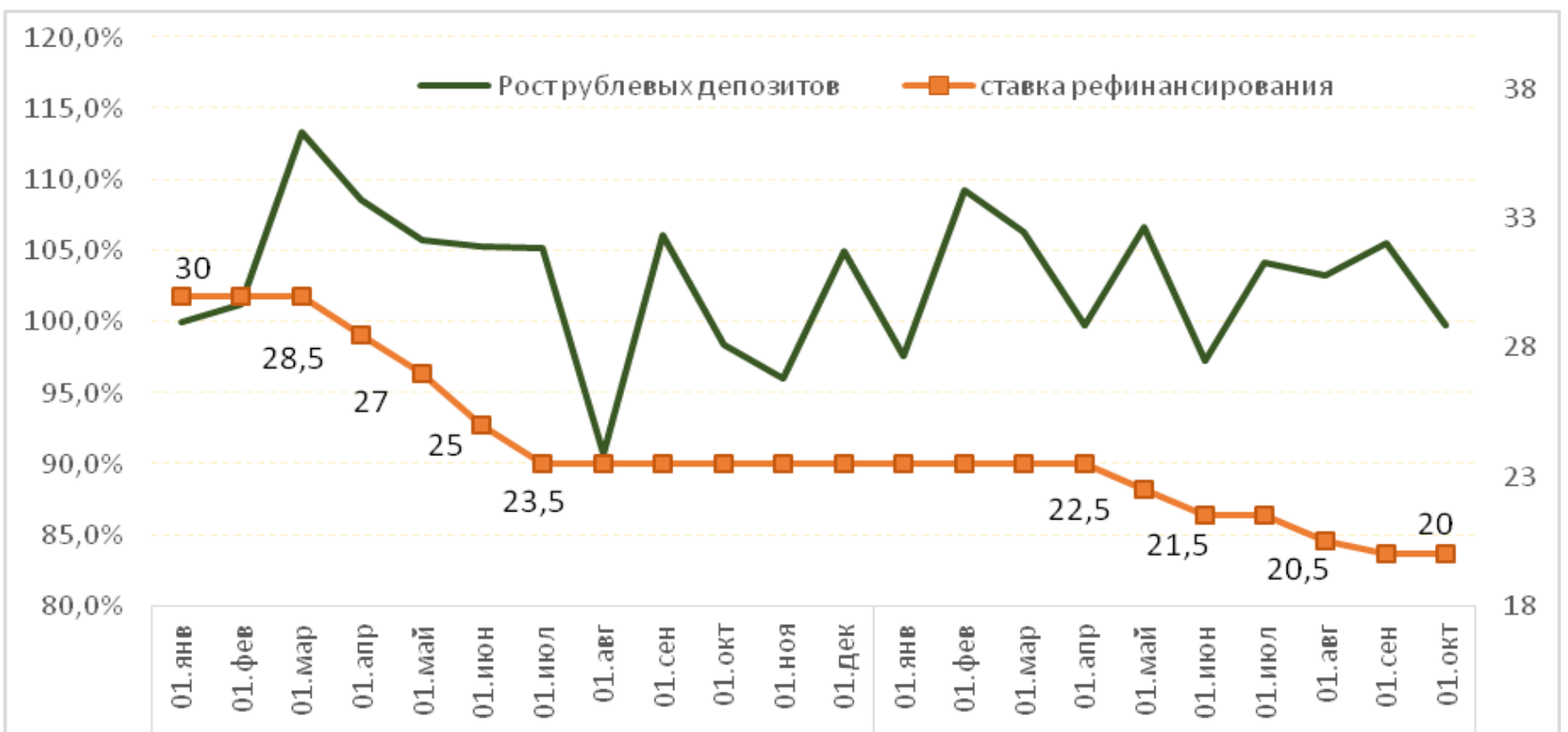

Рисунок 2 - Изменение рублевых депозитов по сравнению с предшествующим месяцем и динамика ставки рефинансирования, \%

Серьезной проблемой является дисбаланс у предприятий реального сектора по состоянию использования квалифицированной рабочей силы и интересов работников по увеличению своих доходов, в том числе путем трудовой миграции в другие страны (наиболее массовая трудовая миграция наблюдается из Беларуси в Россию). Для согласования интересов домашних хозяйств в повышении своих доходов и в связи с потребностью сохранить кадры руководство промышленных предприятиях вынуждено повышать заработную плату более высокими темпами, чем растет производительность труда. Причем эта тенденция усугубляется. Если в 2000-2012 гг. при росте производительности труда на 1\% реальная заработная плата увеличивалась на 1,9 \%, в 2013 г. - на 7,2 \%, то за 9 месяцев 2014 г. по сравнению с соответствующим периодом прошлого года реальная заработная плата выросла на $118,7 \%$, а производительность труда - на 101,8\% [19], то есть на 1\% прироста производительности труда реальная заработная плата увеличилась на $10,4 \%$.

Решить проблему директивным ограничением роста заработной платы по сравнению с производительностью не представляется возможным в связи с необходимостью поддержания определенного паритета уровня жизни в Республике Беларусь с сопредельными странами (прежде всего, с другой страной Евразийского экономического союза - Россией). Выход из данной ситуации видится в росте производительности труда как за счет технического обновления производства, так и за счет структурных реформ и ликвидации неэффективных производств с организованным перераспределением рабочей силы. Это позволит минимизировать противоречия экономических интересов на микроуровне и облегчит согласование интересов на уровне социальных макрогрупп (поскольку снизится заинтересованность в бюджетной и кредитной поддержке неэффективных предприятий).

Наличие объективно обусловленных противоречий между экономическими интересами различных социальных макрогрупп требует совершенствования механизмов согласования этих интересов.

А.А. Лукьянова для согласования системы экономических интересов предложила выделить стабилизационную, структурную и социальную политику государства. При этом стабилизационная политика направлена на сглаживание краткосрочных изменений в системе экономических интересов и предполагает главным образом регулирование совокупного спроса как более динамичного компонента макроэкономического равновесия, структурная политика в большей степени влияет на долгосрочную динамику системы экономических интересов и связана с воздействием на совокупное предложение. При этом интересы домашних хозяйств должна защищать социальная политика государства [20]. В целом, соглашаясь с предложенным подходом, считаем необходимым отметить, что государство должно взять на себя и функцию согласования интересов различных социальных макрогрупп.

Для такого согласования мер законодательного регулирования явно недостаточно в силу того, что оно происходит не только на уровне действующих правовых норм, но и путем применения неформальных норм, выражающихся в достижении взаимных договоренностей, использовании административного нажима и прочих неофициальных методов. Необходимость учета неформальных норм осознали даже судебные органы, которые все чаще прибегают к практике несудебной медиации, когда сторонам предлагается заключить мировое соглашение на принципах, которые могут существенно отклоняться от оговоренных в законодательных актах, но вполне соответствующих неформальным нормам, действующим в обществе.

Поэтому для согласования экономических интересов социальных макрогрупп приоритетными задачами институциональной политики должно быть не только совершенствование формирования системы правовых институтов, регулирующих экономическую деятельность, но и повышение уровня разработки инструментов регулирования системы неформальных институтов, которые позволят более сбалансированно регулировать экономические интересы с целью получения максимально эффекта от использования всех видов материальных, трудовых и финансовых ресурсов, 
ограничат возможность получения отдельными социальными макрогруппами преференций в ущерб экономическим интересам других социальных макрогрупп. Это повысит стабильность социально-экономического развития страны и обеспечит улучшение качества экономического роста.

В таких условиях возникает необходимость создания при Совете Министров координирующей комиссии из представителей различных социальных макрогрупп. Основными задачами этой комиссии должно стать:

- координация деятельности министерств, ведомств и организаций по разработке проектов программ по дальнейшему социально-экономическому развитию и реализации интересов основных социальных групп;

- подготовка докладов и планов действий по согласованию экономических интересов социальных макрогрупп и обеспечению сбалансированного институционального развития;

- рассмотрение и анализ представляемых министерствами докладов и аналитических материалов об их деятельности по обеспечению сбалансированности экономического развития в разрезе видов экономической деятельности с учетом экономических интересов населения и других социальных макрогрупп;

- рассмотрение предложений по перераспределению бюджетных ресурсов и льготных кредитов между министерствами, ведомствами и организациями. При этом следует согласиться со специалистами Министерства экономики Республики Беларусь в том, что налогово-бюджетная политика в нашей стране является недостаточно эффективной, поскольку значительный объем бюджетных средств используется на финансирование и льготирование предприятий в форме государственной поддержки в ущерб расходам, направленным на повышении человеческого потенциала (наука, образование, здравоохранение); порядок формирования доходов бюджета является следствием формирования расходов бюджета, а не наоборот. Доходная часть бюджета формируется после согласования расходов бюджета. При возникновении необходимости привлечения дополнительных доходов в бюджет это приводит к ухудшению финансового состояния рентабельных предприятий [21].

Составным элементом институциональной политики должно стать создание условий в экономической сфере, которые позволили бы постепенно перейти к индикативному планированию, что потребует:

- наряду с подготовкой нормативной правовой базы индикативного планирования осуществить работу по ее признанию на уровне неформальных норм и правил, что требует постепенного переучивания и перестройки работы всех органов государственного управления;

- создание институциональных условий для постепенного отказа от доведения субъектам хозяйствования обязательных для выполнения показателей;

- формирование системы управления государственными предприятиями, обеспечивающей реализацию общегосударственных интересов без доведения обязательных к выполнению показателей подведомственным организациям со стороны министерств и ведомств;

- создание системы мониторинга эффективности управления при переходе на индикативное планирование с соответствующей коррекцией в случае сбоев в новой системе управления.

\section{ВЫВОДЫ}

Для разработки механизма согласования экономических интересов на макроэкономическом уровне предлагается ввести в экономический оборот термин «социальная макрогруппа», под которым понимается объединение людей со специфической ролью в экономической деятельности, ориентированных на реализацию групповых и личных интересов членов социальной группы с использованием формальных и неформальными норм (институтов), и обладающих влиянием, которое позволяет представителям группы участвовать в определении специфики монетарной, фискальной и институциональной политики, воздействовать на основные макроэкономические пропорции, существенно корректировать финансовые потоки в экономике.

Социальные макрогруппы выполняют функции: (а) агрегирования интересов членов социальной макрогруппы, формирования иерархии интересов по степени приоритетности и формулирования на этой основе общегрупповых целей и очередности их достижения; (б) разработки мероприятий и реализации интересов социальной макрогруппы путем транслирования своих интересов в органы государственного управления, путем взаимодействия с этими структурами и средствами массовой информации; (в) участия в подборе кадров, выдвижении своих представителей в органы государственного управления для реализации своих групповых интересов.

Приоритетной задачей государственной институциональной политики, наряду с дальнейшим совершенствованием правовых институтов, должна стать разработка инструментов регулирования системы неформальных институтов, позволяющих эффективно согласовывать экономические интересы с целью получения максимального эффекта от использования всех видов материальных, трудовых и финансовых ресурсов, ограничения возможности получения отдельными социальными группами необоснованных преференций в ущерб экономическим интересам других социальных групп.

Для согласования экономических интересов социальных макрогрупп рекомендуется создать при Совете Министров координирующий орган из представителей различных социальных макрогрупп. Основными задачами этого органа должны стать: (а) координация деятельности по разработке проектов программ социально-экономического развития и реализации интересов социальных макрогрупп (в том числе домашних хозяйств); (б) рассмотрение предложений по распределению льготных кредитов, налоговых и бюджетных льгот между министерствами, ведомствами и организациями; (в) проведение процедур медиации (согласования интересов с участием третьей стороны) при наличии существенных разногласий между представителями различных социальных макрогрупп. 
Составным элементом институциональной политики должно стать создание условий в экономической сфере, которые позволили бы постепенно перейти к индикативному планированию, что потребует: (а) формирования новой системы государственных приоритетов с устранением из нее достижения заданных параметров объемных показателей; (б) осуществления работы по ее признанию на уровне неформальных норм и правил с переучиванием специалистов органов государственного управления, наряду с подготовкой нормативной правовой базы индикативного планирования; (в) создание системы мониторинга эффективности управления при переходе на индикативное планирование с соответствующей коррекцией в случае возникающих сбоев.

Необходимо повысить роль ставки рефинансирования как инструмента регулирования монетарной политики. Рекомендуется устанавливать ставку рефинансирования на уровне, обеспечивающем учет интересов. Недопустим отрыв депозитных ставок более, чем на 5 п.п. от ставки рефинансирования. Сама же ставка рефинансирования должна быть выше прогнозируемых среднегодовых темпов инфляции не менее, чем на 3 п.п., обеспечивая выгодность депозитов в белорусских рублях.

\section{ЛИТЕРАТУРА}

1. «In macroeconomics, the balanced-growth path of a dynamic model is a trajectory such that all variables grow at a constant rate. In the standard exogenous growth» [Электронный ресурс] - Режим доступа : http://en.wikipedia.org/wiki/Balanced-growth equilibrium» - Дата доступа : 10.09.2014.

2. Balanced Growth refers to a specific type of economic growth that is sustainable in the long term. Balanced growth is opposed to the boom and bust nature of economic cycles [Electronic resource] - Mode of access : http://www.economicshelp.org/blog/glossary/balanced-growth. - Date of access : 19.06.2014.

3. Словарь синонимов [Электронный ресурс] / Н. Абрамов. Москва, 1999. - Режим доступа : http://dic.academic.ru/dic.nsf/dic_synonims. - Дата доступа: 01.09.2014.

4. Социальные группы и организации [Электронный ресурс] - Режим доступа : http://www.grandars.ru/college/sociologiya/socialnaya-gruppa.html. - Дата доступа : 10.04.2014.

5. Андреева, М. Социальная психология [Электронный ресурс] - Третье издание, М.: Наука, 1994. - Режим доступа : http://psylib.org.ua/books/andrg01/txt09.htm. -Дата доступа : 10.04.2014.

6. Мау, В. Национально-государственные интересы и социально-экономические группы / В. Мау // Вопросы экономики. - 1994. - № 2. - С. 54-63. - С. 55, 57.

7. Антиинфляционная политика России [Электронный ресурс]. - Режим доступа http://www.grandars.ru/student/ekonomicheskaya-teoriya/antiinflyacionnaya-politika. html. - Дата доступа : 03.03.2014.

8. Основные цели антиинфляционной политики [Электронный ресурс]. - Режим доступа: http://uchebnikbesplatno.com/ekonomika-uchebnik/antiinflyatsionnaya-politika-tsel-osnovnyie.html. Дата доступа: 03.03.2014.

9. Формы и методы антиинфляционной политики [Электронный ресурс]. - Режим доступа: http://be5.biz/ekonomika/f007/50.htm. Дата доступа: 03.03.2014.

10. Малкина, М. Ю. Инфляция: теория и практика / М.Ю. Малкина // Финансы и кредит. - 2006. - №12 - С. $26-$ 32.

11. Об Основных направлениях денежно-кредитной политики Республики Беларусь на 2014 год: Указ Президента Респ. Беларусь, 31.12.2013, № 586 [Электронный ресурс] / Национальный банк Респ. Беларусь. - Минск, 2014. Режим доступа : http://www.nbrb.by/Legislation/documents/ondkp-2014.pdf. - Дата доступа : 20.07.2014.

12. «I have so far stated that inflation is always and everywhere a monetary phenomenon in the sense that it is and can be produced only by a more rapid increase in the quantity of money than in output». M. Friedman "The Counter- Revolution in Monetary Theory" IEA Occasional Paper, no. 33 [Электронный ресурс] - Режим доступа: http://0055d26.netsolhost.com/friedman/pdfs/other_academia/IEA.1970.pdf. - Дата доступа: 12.03.2014.

13. О республиканском бюджете на 2014 год: Закон Респ. Беларусь, 31 декабря 2013 г., № 95-3. [Электронный pecypc] / Нац. Центр правовой информ. Респ. Беларусь. - Минск, 2014. - Режим доступа : http://pravo.by/main.aspx ?guid=12551\&p0=H11300095\&p1=1. - Дата доступа : 25.08.2014.

14. Основные тенденции в экономике и денежно-кредитной сфере Республики Беларусь [Электронный ресурс]: аналит. обозрение. - Январь-июнь 2014 г. Национальный банк Республики Беларусь. - Минск, 2014. - Режим доступа : http://www.nbrb.by/publications/EcTendencies/rep_2014_06_ot.pdf. Дата доступа : 15.09.2014.

15. Республика Беларусь в зеркале социологии : сб. материалов социол. исслед. за 2012 год / В.О. Дашкевич [и др.]; под общ.ред. Л.Е. Криштаповича; Информационно-аналитический центр при Администрации Президента Республики Беларусь. - Минск : Бизнесофсет, 2014. - С.8.

16. Об утверждении Устава Национального банка Республики Беларусь: Указ Президента Респ. Беларусь, 13 июня 2001 г., № 320 [Электронный ресурс] / Нац. Центр правовой информ. Респ. Беларусь. - Минск, 2014. - Режим доступа : http://www.pravo.by/main.aspx?guid=3871\&p0=P30100320\&p2=\{NRPA. Дата доступа : 15.09.2014.

17. Румас, С., Плешкун, А. Сбережения населения: оценка, тенденции, факторы роста/ С. Румас // Банковский вестник. - 2010. - №9. - С. 9.

18. Митрофанова, Т. Новые подходы к финансированию государственных программ: выбор приоритетов и принципов работы, финансовая поддержка МСБ [Электронный ресурс]. - Режим доступа : http://kef.research.by/webroot/delivery/files/KEF-2014_conference20141105r_Mitro-fanova.pdf. Дата доступа 06.11.2014. 
19. Социально-экономическое положение Республики Беларусь в январе-сентябре 2014 г. [Электронный ресурс] / Нац. стат. комитет Респ. Беларусь. - Минск, 2014. - Режим доступа: http://belstat.gov.by/uploads/bgd_files/1414162311916199.zip. - Дата доступа: 30.10.2014.

20. Лукьянова, А.А. Согласование экономических интересов в системе государственного регулирования социально-экономических процессов : дис. канд. экон. наук : 08.00.01 /А.А. Лукьянова. - Пенза, 2006. - 193 с.

21. Оценка итогов социально-экономического развития Республики Беларусь, угроз национальной безопасности и предложения по их преодолению: аналит. записка / Министерство экономики Респ. Беларусь. - Минск, 2014. $8 \mathrm{c}$.

Статья поступила в редакциию 14 июня 2015 года. 